\title{
Application of artificial intelligence techniques for LFC and AVR systems using PID controller
}

Ghassan Abdullah Salman, Assama Sahib Jafar, Ammar Issa Ismael

Department of Electrical Power and Machines Engineering, College of Engineering, University of Diyala, Diyala, Iraq

\begin{tabular}{|c|c|}
\hline Article Info & ABSTRACT \\
\hline Article history: & Development of electrical power systems led to search for a new \\
\hline Received Nov 19, 2018 & $\begin{array}{l}\text { mathematical methods to find the values of PID (Proportional-Integral- } \\
\text { Derivative) controller. The goal of the paper is to improve the performance }\end{array}$ \\
\hline Revised Feb 11, 2019 & of the overall system, through improved the frequency deviation and the \\
\hline Accepted Apr 22, 2019 & $\begin{array}{l}\text { voltage deviation characteristics using PID controller, so in this paper are } \\
\text { proposed three methods of artificial intelligence techniques for designing the }\end{array}$ \\
\hline Keywords: & $\begin{array}{l}\text { optimal values of PID controller of Load-Frequency-Control (LFC) and } \\
\text { Automatic-Voltage-Regulator (AVR), the first is the Firefly Algorithm (FA), } \\
\text { the second is the Gentic Algorithm (GA) and the third is the Particle Swarm }\end{array}$ \\
\hline AVR & Optimization (PSO), in addition to these three methods use the conventional \\
\hline Fitness Function & (Ziegler-Nichols, Z-N). The FA, GA and PSO are used to obtain the optimal \\
\hline LFC & parameters of PID controller based on minimized different various indices as \\
\hline Optimization Technique & a fitness function, these fitness functions namely Integral-Time-Absolute- \\
\hline PID controller & $\begin{array}{l}\text { Error (ITAE) and Integral-Time-Square-Error (ITSE). Comparison between } \\
\text { the results obtained show that FA has better performance to control of } \\
\text { frequency deviation and terminal voltage than GA and PSO, so the results } \\
\text { observed the FA is more effectual and reliable to determine the optimal } \\
\text { values of PID controller. }\end{array}$ \\
\hline
\end{tabular}

Copyright @ 2019 Institute of Advanced Engineering and Science. All rights reserved.

\author{
Corresponding Author: \\ Ghassan Abdullah Salman, \\ Departement of Electrical Power and Machins Engineering, \\ Collage of Engineering, \\ University of Diyala, \\ Baqubah, Diyala, Iraq. \\ Email: ghassanpowerz@gmail.com
}

\section{INTRODUCTION}

Both LFC and AVR plays an important and essential role in the control of power generation systems in order to be suitable for the consumer, through the control of (active power - frequency) and (reactive power - voltage) respectively, so that the deviation values must be within acceptable limits $[1,2]$. First of all influence between the mechanical and electrical parts precisely, interconnection equations between LFC and AVR have been proposed by $[3,4]$. The coordination between LFC and AVR with the new model has been proposed by [5]. The oscillation of LFC and AVR are studied with PID controller in [6, 7] to improve the performance of two control loops. To more efficient results the artificial intelligence techniques was used for tuning the gains of PID controller for LFC with AVR loops, the applications of artificial intelligence technique based on optimization of PID controller for LFC are presented in [8-12], whereas the optimal design of PID controller by using artificial intelligence technique for AVR system are presented in [13-17]. The LFC and AVR control loops with tuning PID parameters by optimization technique are studied individually in $[18,19]$, while the interaction effect among the LFC with AVR control loops with optimized the PID controller gains are presented in [20-22].

The paper problem lies in tuning the optimal values of the PID controller on the LFC and AVR systems and thus improving the general performance of the system by improving frequency and voltage 
deviations, Finally, for this paper the performance of LFC with AVR loops for single area power system have been studied and it is implementation FA, GA and PSO for tuning the parameters of PID based to minimize two different fitness functions. First is ITAE and second is ITSE.

\section{MODELING OF LFC AND AVR SYSTEMS}

The effect of coupling and coordination between LFC and AVR are studied in this paper, a full description of the transfer function model for LFC and AVR loops are presented in [2, 6] and shown in Figure 1.

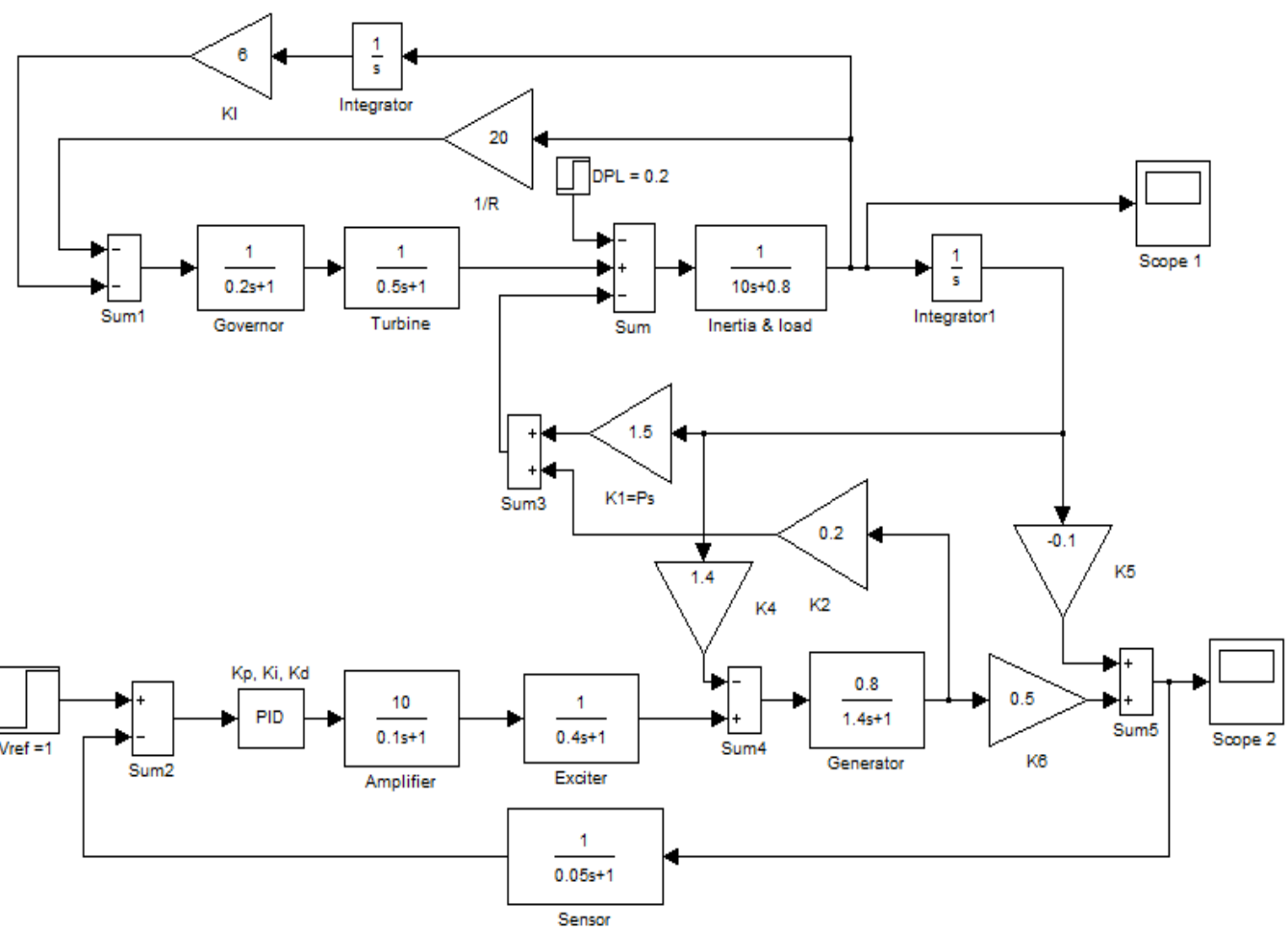

Figure 1. MATLAB/Simulink model from LFC and AVR system

According to $[2,5]$ from the interaction among LFC with AVR loops obtain the following equations:

$$
\begin{aligned}
& \Delta \mathrm{P}_{\mathrm{e}}=\mathrm{K}_{1} \Delta \delta+\mathrm{K}_{2} \Delta \mathrm{E}_{\mathrm{q}}^{\prime} \\
& \Delta \mathrm{E}_{\mathrm{q}}^{\prime}=\frac{\mathrm{K}_{3}}{1+\mathrm{K}_{3} \mathrm{~T}_{\mathrm{d} 0}^{\prime} \mathrm{s}} \Delta \mathrm{E}_{\mathrm{FD}}-\frac{\mathrm{K}_{3} \mathrm{~K}_{4}}{1+\mathrm{K}_{3} \mathrm{~T}_{\mathrm{d} 0}^{\prime} \mathrm{s}} \Delta \delta \\
& \Delta \mathrm{V}_{\mathrm{t}}=\mathrm{K}_{5} \Delta \delta+\mathrm{K}_{6} \Delta \mathrm{E}_{\mathrm{q}}^{\prime}
\end{aligned}
$$

\section{MODELING OF THE PID CONTROLLER}

The PID controller still the dominant play an important role in power systems, for ease of representation and implementation, as well as to its effectiveness in enhancement the performance of electrical power systems. According to [7, 21] Figure 2 shows the typical structure of PID controller.

Application of artificial intelligence techniques for LFC and AVR systems ... (Ghassan Abdullah Salman) 


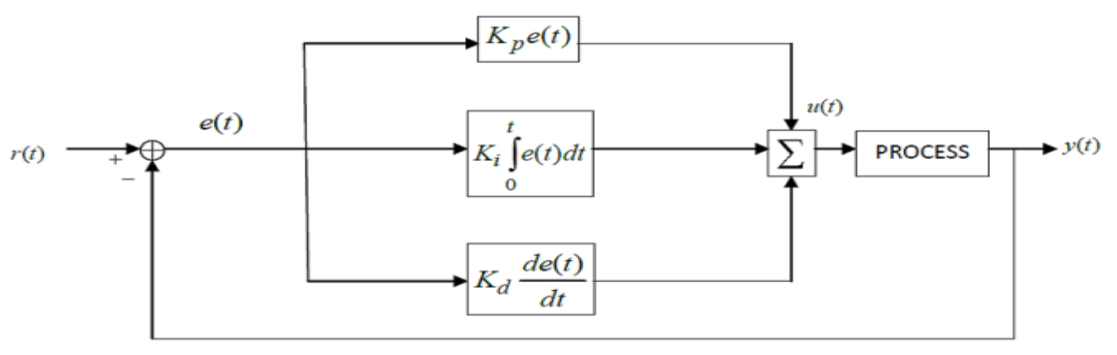

Figure 2. Block diagram of the PID controller

The PID controller transfer function model in terms of Laplace domain is qualified as follow:

$$
\mathrm{G}_{\mathrm{PID}}(\mathrm{s})=\frac{\mathrm{U}(\mathrm{s})}{\mathrm{E}(\mathrm{s})}=\mathrm{k}_{\mathrm{p}}+\frac{\mathrm{k}_{\mathrm{i}}}{\mathrm{s}}+\mathrm{k}_{\mathrm{d}} \mathrm{s}
$$

Where, $\mathrm{E}(\mathrm{s})$ with $\mathrm{U}(\mathrm{s})$ are the error signal and the control signal that represented the variation among input and feedback in expression of Laplace domain on the other; $\mathrm{k}_{\mathrm{p}}$ represent the proportional gain, $\mathrm{k}_{\mathrm{i}}$ represent the integration gain and $\mathrm{k}_{\mathrm{d}}$ represent the derivative gain. The PID controller output in term of time domain is represented as follow:

$$
u(t)=k_{p} e(t)+k_{i} \int_{0}^{t} e(t) d t+k_{d} \frac{d e(t)}{d t}
$$

Where, $\mathrm{e}(\mathrm{t})$ and $\mathrm{u}(\mathrm{t})$ are tracking error and the control signals that represent in the form of time domain.

Finally, in this paper the effect of two different objective functions is studied for optimization to determine the parameters of PID controller. First is ITAE and second is ITSE. Has been defined as follows:

$$
\begin{aligned}
& \text { ITAE }=\int_{0}^{t} t\left[\left|\mathrm{e}_{1}(\mathrm{t})\right|+\left|\mathrm{e}_{2}(\mathrm{t})\right|\right] \mathrm{dt} \\
& \operatorname{ITSE}=\int_{0}^{\mathrm{t}} t\left[\left(\mathrm{e}_{1}\right)^{2}(\mathrm{t})+\left(\mathrm{e}_{2}\right)^{2}(\mathrm{t})\right] \mathrm{dt}
\end{aligned}
$$

Minimize ITAE and ITSE subjected to:

$$
\mathrm{k}_{\mathrm{p}}^{\min } \leq \mathrm{k}_{\mathrm{p}} \leq \mathrm{k}_{\mathrm{p}}^{\max }, \mathrm{k}_{\mathrm{i}}^{\min } \leq \mathrm{k}_{\mathrm{i}} \leq \mathrm{k}_{\mathrm{i}}^{\max } \text { and } \mathrm{k}_{\mathrm{d}}^{\min } \leq \mathrm{k}_{\mathrm{d}} \leq \mathrm{k}_{\mathrm{d}}^{\max }
$$

\section{CONTROL STRATEGY OF PID CONTROLLER}

\subsection{Conventional (Z-N) Method [20, 23-25]}

In the fourth decade of the last century, Ziegler and Nichols presented the values of $K_{p}, T_{i}$ and $T_{d}$ according to the rules shown in Table 1.

By this method, the dynamic property of the procedure is represented by the final gain from a consistent controller and the final pulse period of the loop. The final gain and a period of actual operation are usually determined by the following process:

a. The derivative and integrated modes of the feedback controllers are turned (off) for this reason they have a relative control.

b. For the automatic control, the relative gain - relative range reduction- is increased into the loop fluctuates for a constant capacity.

c. For the help of time register for the controlled variable, the pulse period is measured and registered as the final T period.

Table 1. Z-N Tuning Rules

\begin{tabular}{cccc}
\hline Type of Controller & $\mathrm{K}_{\mathrm{p}}$ & $\mathrm{T}_{\mathrm{i}}$ & $\mathrm{T}_{\mathrm{d}}$ \\
\hline $\mathrm{P}$ & $\mathrm{T} / \mathrm{L}$ & $\infty$ & 0 \\
$\mathrm{PI}$ & $0.9 * \mathrm{~T} / \mathrm{L}$ & $\mathrm{L} / 0.3$ & 0 \\
PID & $1.2 * \mathrm{~T} / \mathrm{L}$ & $2 \mathrm{~L}$ & $0.5 \mathrm{~L}$ \\
\hline Note: $\mathrm{k}_{\mathrm{p}}=\mathrm{K}_{\mathrm{p}}, \mathrm{k}_{\mathrm{i}}=\mathrm{K}_{\mathrm{p}} / \mathrm{T}_{\mathrm{i}}$ and $\mathrm{k}_{\mathrm{d}}=\mathrm{K}_{\mathrm{p}} * \mathrm{~T}_{\mathrm{d}}$ &
\end{tabular}

Int J Pow Elec \& Dri Syst, Vol. 10, No. 3, Sep 2019 : 1694 - 1704 


\subsection{Intelligence techniques}

The modern artificial intelligence and heuristics techniques play an important role to control of electric power system therefore, the main objective of this paper for control the frequency deviation and terminal voltage deviation of single area power system. At first controller parameters tuning is accomplished by conventional $(\mathrm{Z}-\mathrm{N})$ procedure. But, this method is not feasible in practical systems that need fast processing and this is not available in this method. Consequently, much powerful mathematical optimization techniques are utilizing to tune the parameters of PID and most reliable are population based optimization procedures especially FA, GA and PSO.

FA is a Meta heuristic search technique based on optimization algorithm; it is proposed in 2007 by Xin She Yang [26]. The FA is described in the following rules.

a. Each firefly has the ability to attract other fireflies of the same sex or of the opposite sex.

b. Firefly brightness is proportional to the attraction and inversely proportional to the distance, thus the low brightness of the firefly moves to a high-brightness firefly near it.

c. The optimum value for the fitness function represented by the brightness of fireflies.

The following equations below describe the FA:

$$
\begin{aligned}
& X_{i}^{\text {new }}=X_{i}^{\text {old }}+\beta\left(X_{j}-X_{i}\right)+\alpha\left(\text { rand }-\frac{1}{2}\right) \\
& \beta=\beta_{0} e^{-\gamma r_{i j}^{m}} \quad(m \geq 1) \\
& r_{i j}=\left\|X_{i}-X_{j}\right\|=\sqrt{\sum_{k=1}^{d}\left(X_{i, k}-X_{j, k}\right)^{2}}
\end{aligned}
$$

Where (9) represents the movement of the Fireflies, where the first expression is the current position of a firefly, the next expression is applied for considering a firefly's attractions to light intensity seen by adjacent fireflies, then the third expression issued for the random movement of a firefly in case, there are no any brighter ones. The coefficient $\alpha$ is a indiscriminate parameter determined by the problem of interest, whilst rand is a random number generator regularly distributed in the space $[0,1]$.

Where $\beta_{0}$ consider the foremost attractiveness at $r$ equal $0, \gamma$ is an absorption coefficient that can controls the decrease from the light intensity and $\mathrm{r}$ consider the dimension among any two fireflies. But $\mathrm{X}_{\mathrm{i}, \mathrm{k}}$ consider the kth component of the locative $X_{i}$ of the ith firefly while $d$ is the dimensions number. GA is introduced by John Holland in 1970; it is a stochastic global search method used for optimization [27]. The GA operators are usually done by following stages [28]-[29].

a. Selection: Operator selection is applied multiple times because there are members in the population. Any individual is iterative at this step together with a eventuality proportional to the relative fitness function of the population.

b. Crossover: The crossover operator is applied to produce two new individuals, by choice and combining two individuals (parents). The collection process is done by random selection of the cut point and then dividing the parents into two parts, so that the parents are replaced by the offspring, formed in the population.

c. Mutation: The values in a site are randomly selected for individual changes by the mutation operator, after the number of iterations that the algorithm has been completed, while running the algorithm represents the best individual solution created.

In 1995 the PSO is developed by Kennedy and Eberhart, it is one of the modern heuristic algorithms used for optimization [30]. In PSO method, set of individuals that make up the swarm called particles, each particle has position and velocity. To reach the optimal values the position and velocity are update using the following equations:

$$
\begin{aligned}
& \mathrm{X}_{\mathrm{i}}^{\mathrm{k}+1}=\mathrm{X}_{\mathrm{i}}^{\mathrm{k}}+\mathrm{V}_{\mathrm{i}}^{\mathrm{k}+1} \\
& \mathrm{~V}_{\mathrm{i}}^{\mathrm{k}+1}=\mathrm{w}_{\mathrm{i}}^{\mathrm{k}}+\mathrm{c}_{1} \mathrm{r}_{1}\left(\mathrm{p}_{\text {best }, \mathrm{i}}^{\mathrm{k}}-\mathrm{X}_{\mathrm{i}}^{\mathrm{k}}\right)+\mathrm{c}_{2} \mathrm{r}_{2}\left(\mathrm{~g}_{\text {best }, \mathrm{i}}^{\mathrm{k}}-\mathrm{X}_{\mathrm{i}}^{\mathrm{k}}\right) \\
& \mathrm{w}=\frac{2}{\left|2-\varphi-\sqrt{\varphi^{2}-4 \varphi}\right|}
\end{aligned}
$$

Where $\mathrm{X}_{\mathrm{i}}^{\mathrm{k}+1}$ is position of particle at $\mathrm{k}+1$ iteration, $\mathrm{X}_{\mathrm{i}}^{\mathrm{k}}$ is position of particle at $\mathrm{k}$ iteration, $\mathrm{V}_{\mathrm{i}}^{\mathrm{k}+1}$ represent velocity form particle at $\mathrm{k}+1$ iteration, $\mathrm{V}_{\mathrm{i}}^{\mathrm{k}}$ represent velocity of particle at $\mathrm{k}$ iteration, $\mathrm{w}$ represent inertia weight parameter, $c_{1}$ with $c_{2}$ are learning factors, $r_{1}$ with $r_{2}$ are random number in the interval $[0,1]$.

Application of artificial intelligence techniques for LFC and AVR systems ... (Ghassan Abdullah Salman) 
The flowchart of FA, GA and PSO based on ITAE and ITSE as a fitness functions to determine optimal values of PID controller as shown at Figure 3, while the parameters from these technique are given in Table 2.

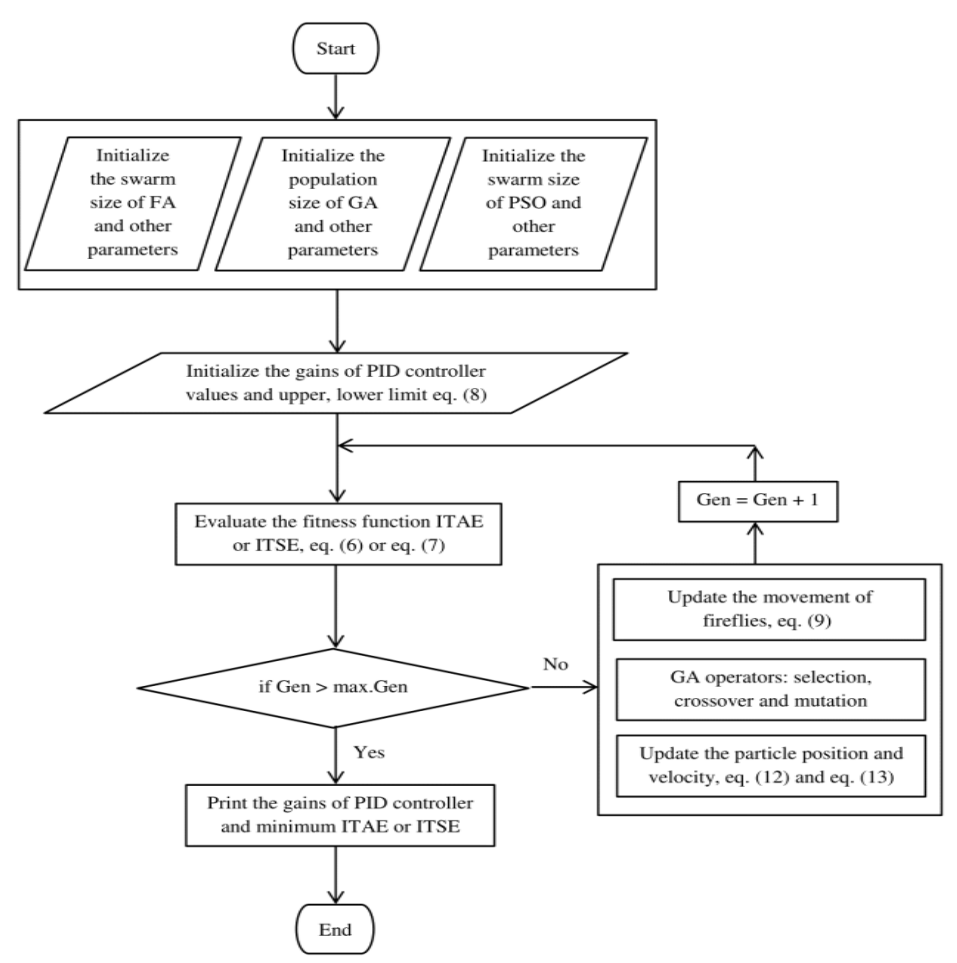

Figure 3. Flowchart of intelligence techniques for PID controller

Table 2. Parameters of FA, GA and PSO

\begin{tabular}{ccc}
\hline FA & GA & PSO \\
\hline Population Size $(\operatorname{Pop})=30$ & Population Size $(P o p)=30$ & Population Size $(P O P)=30$ \\
Absorption Coefficient $(\gamma)=0.5$ & Crossover Factor $(\gamma)=0.5$ & $\varphi_{1}=2, \varphi_{2}=2.1$ and $\varphi=\varphi_{1}+\varphi_{2}$ \\
Attraction Coefficient $\left(\beta_{0}\right)=0.2$ & Crossover Percentage $(p c)=0.8$ & Inertia Weight $(w)=$ Eq. $(14)$ \\
Mutation Coefficient $(\alpha)=0.3$ & Mutation Percentage $(p m)=0.3$ & Personal Learning Coefficient $\left(C_{1}\right)=w^{*} \varphi_{1}$ \\
$m=3$ & Mutation Rate $(m u)=0.1$ & Global Learning Coefficient $\left(C_{2}\right)=w^{*} \varphi_{2}$ \\
\hline
\end{tabular}

\section{SIMULATION RESULTS AND DISCUSSION}

The implementation coupling between LFC with AVR loops for single area power system and PID controller that shown at Figure 4, the LFC with AVR control loops as presented individually in the papers $[18,19]$. Table 3 gives the PID gain, which is set in the conventional (Z-N) method.

Then, for enhancing the terminal voltage and the frequency oscillation of single area power system, the optimal values of PID controller are obtained by FA, GA and PSO with ITAE and ITSE fitness functions, the ITAE take as a fitness function to obtained the optimal values of PID controller is shown in Figure 5, whereas Figure 6 shows the ITSE takes as a fitness function to obtained the optimal values of PID controller. The lower bound of PID gain is chosen as 0 and the upper bound is chosen as 3 . Therefore, the optimal values of the PID gains to minimize the ITAE and ITSE are computed by FA, GA and PSO, also these values of PID controller are given at Table 4.

Int J Pow Elec \& Dri Syst, Vol. 10, No. 3, Sep 2019 : $1694-1704$ 


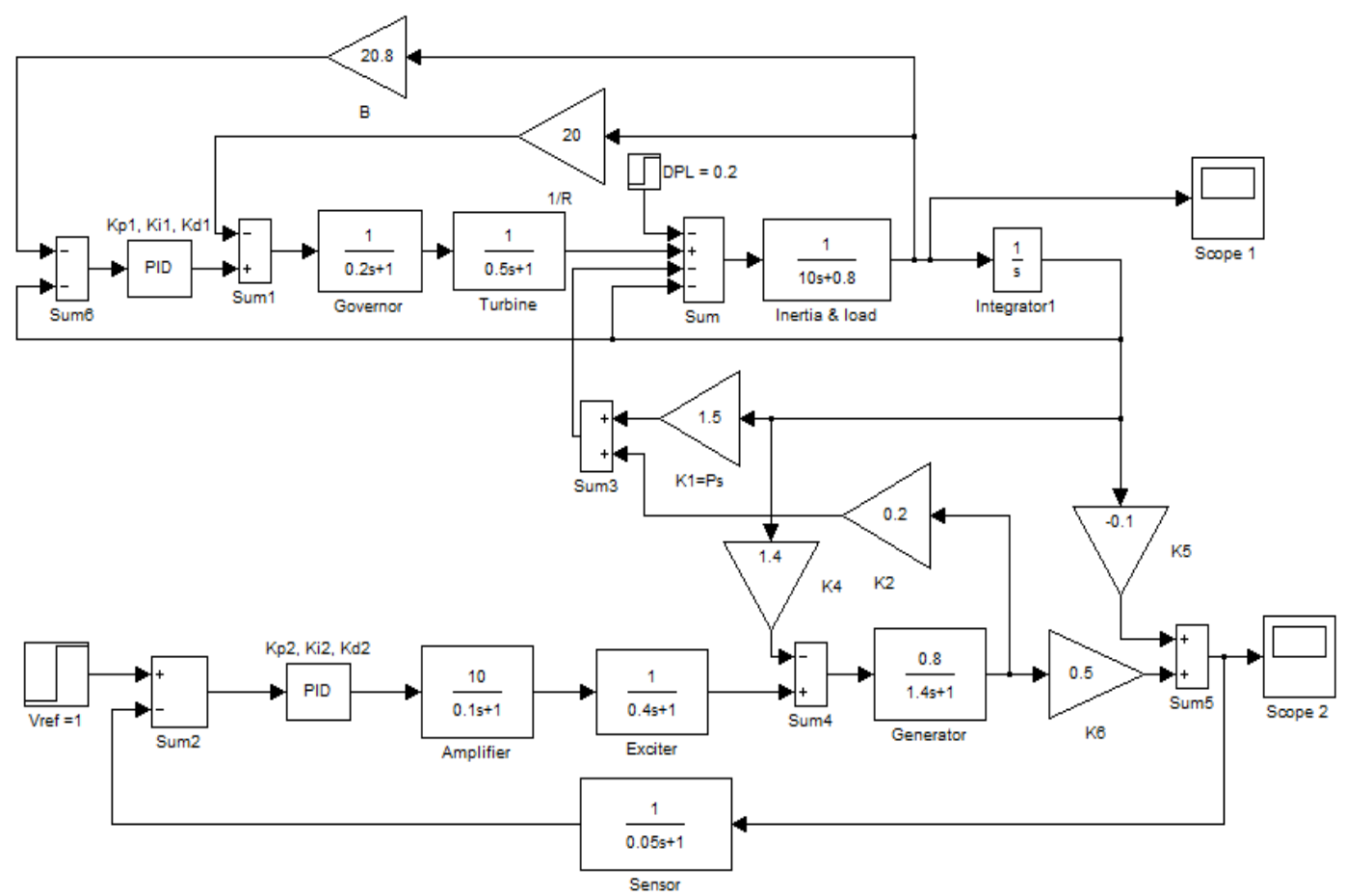

Figure 4. MATLAB/simulation model of LFC with AVR system with PID controller

Table 3. Gains of PID Controller by Z-N Method

\begin{tabular}{cccccc}
\hline $\mathrm{k}_{\mathrm{p} 1}$ & $\mathrm{k}_{\mathrm{i} 1}$ & $\mathrm{k}_{\mathrm{d} 1}$ & $\mathrm{k}_{\mathrm{p} 2}$ & $\mathrm{k}_{\mathrm{i} 2}$ & $\mathrm{k}_{\mathrm{d} 2}$ \\
\hline 1.6028 & 2.0254 & 1.3137 & 0.9523 & 0.3515 & 0.2018 \\
\hline
\end{tabular}

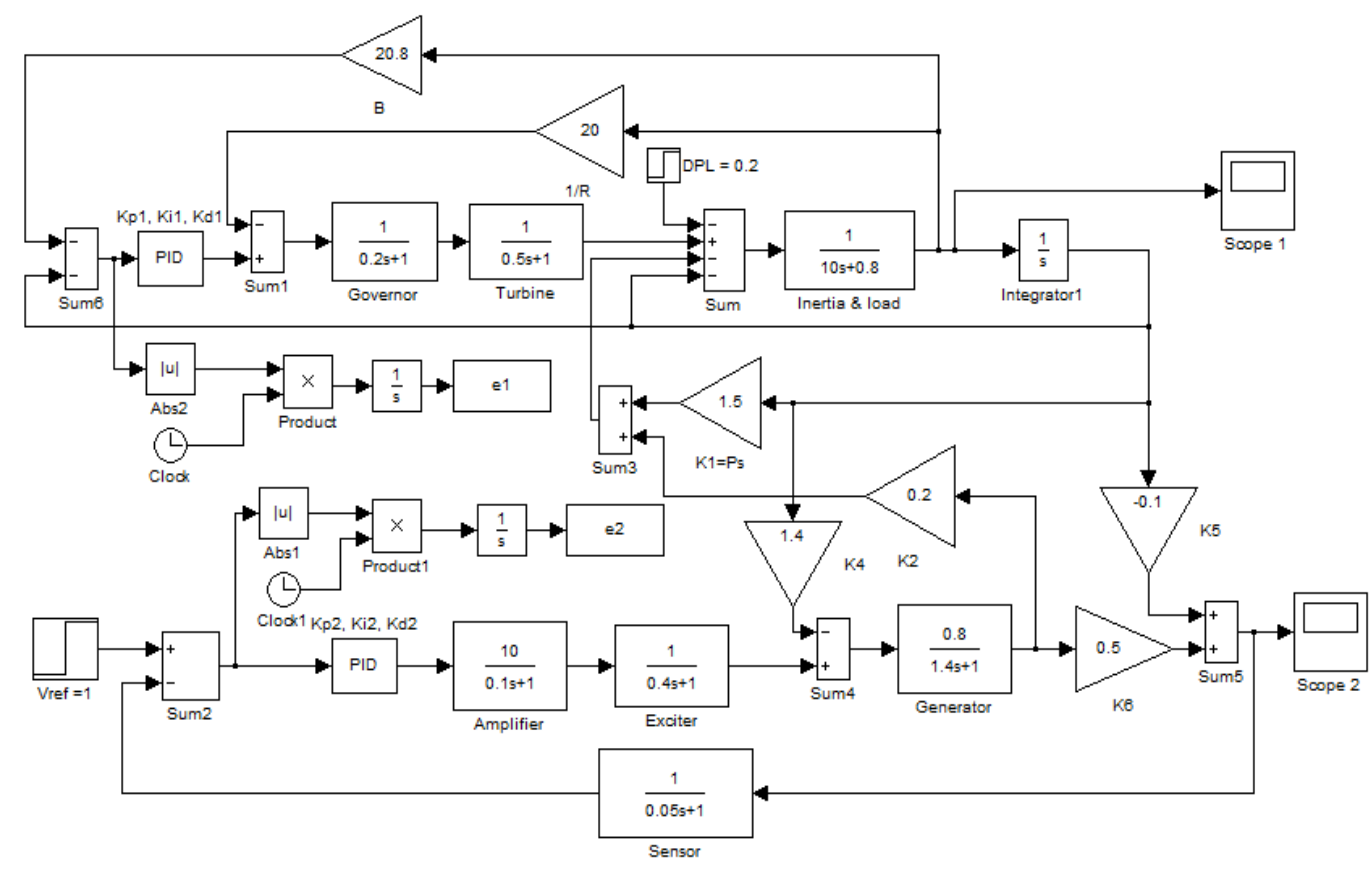

Figure 5. MATLAB/ simulation model form LFC with AVR system based on ITAE 


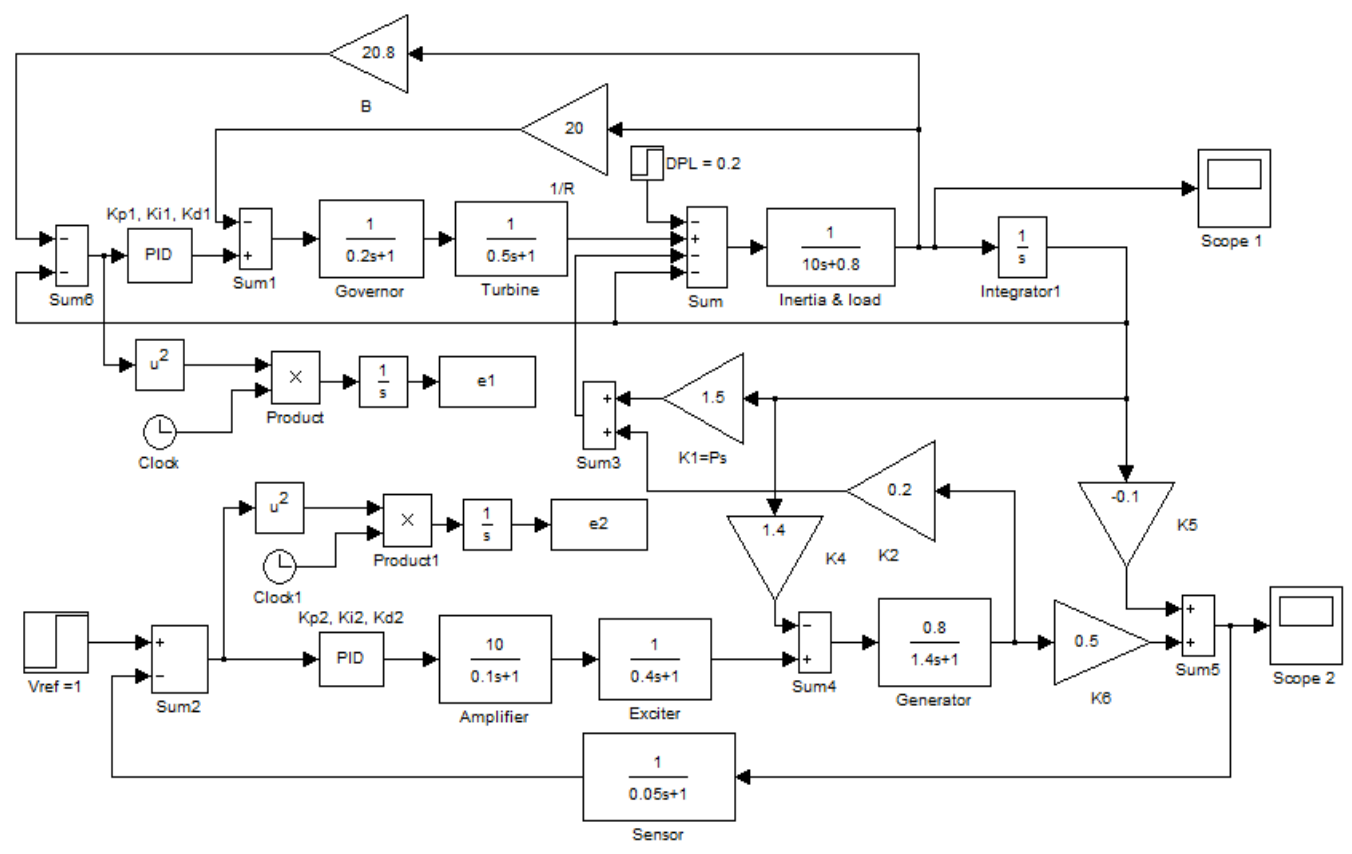

Figure 6. MATLAB/ simulation model from LFC with AVR system based on ITSE

Table 4. Optimal gains of PID controller by FA, GA and PSO

\begin{tabular}{ccccccc}
\hline & $\mathrm{k}_{\mathrm{p} 1}$ & $\mathrm{k}_{\mathrm{i} 1}$ & $\mathrm{k}_{\mathrm{d} 1}$ & $\mathrm{k}_{\mathrm{p} 2}$ & $\mathrm{k}_{\mathrm{i} 2}$ & $\mathrm{k}_{\mathrm{d} 2}$ \\
\hline FA-ITAE & 2.9931 & 2.9972 & 2.4862 & 2.6872 & 0.5717 & 0.7283 \\
FA-ITSE & 2.9850 & 2.9916 & 2.4238 & 2.8715 & 0.5821 & 0.7764 \\
GA-ITAE & 2.6959 & 2.9638 & 2.2359 & 2.3915 & 0.5984 & 0.6293 \\
GA-ITSE & 2.6231 & 2.4978 & 2.3509 & 2.4868 & 0.6441 & 0.6637 \\
PSO-ITAE & 2.7789 & 2.9868 & 2.3592 & 2.5751 & 0.5803 & 0.6883 \\
PSO-ITSE & 2.8192 & 2.7951 & 2.4026 & 2.7821 & 0.6202 & 0.7518 \\
\hline
\end{tabular}

Figures 7 and 8 shows the frequency deviation response to adjust the PID controller by FA, GA and PSO on the basis of ITAE and ITSE compared to the conventional (Z-N) method, while the characteristics of the frequency deviation (maximum-deviation, peak-time,then settling-time and finaly steady-state-error) are given at Table 5 compared with results are presented in papers $[18,19]$.

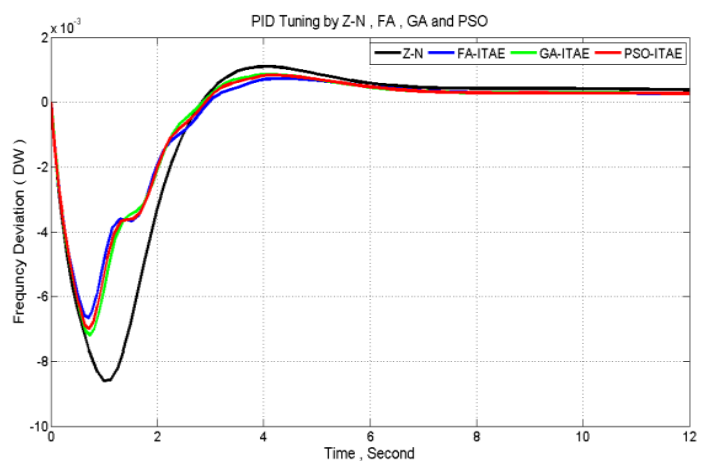

Figure 7. Frequency Deviation and PID tuning using FA, GA with PSO based on ITAE compared with Z-N

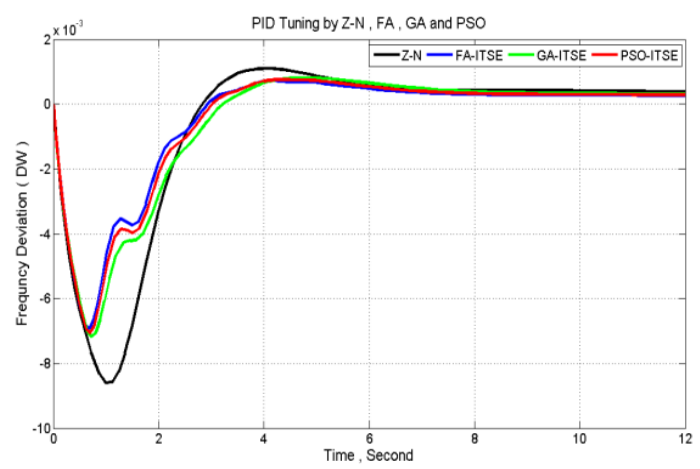

Figure 8. Represent frequency deviation and PID tuning using FA, GA with PSO based on ITSE compared with Z-N 
Table 5. Frequency deviation characteristics and PID tuning using Z-N, FA, GA and PSO

\begin{tabular}{ccccc}
\hline & $\mathrm{M}_{\mathrm{d}}(\mathrm{p} . \mathrm{u})$ & $\mathrm{t}_{\mathrm{p}}(\mathrm{sec})$. & $\mathrm{t}_{\mathrm{s}}(\mathrm{sec})$. & $\mathrm{E}_{\mathrm{ss}}(\mathrm{p} . \mathrm{u})$ \\
\hline Z-N & $-8.597 \times 10^{-3}$ & 0.9976 & 9.441 & $-3.816 \times 10^{-4}$ \\
FA-ITAE & $-6.666 \times 10^{-3}$ & 0.7040 & 8.726 & $-2.627 \times 10^{-4}$ \\
FA-ITSE & $-6.917 \times 10^{-3}$ & 0.6893 & 8.671 & $-2.608 \times 10^{-4}$ \\
GA-ITAE & $-7.194 \times 10^{-3}$ & 0.7363 & 8.993 & $-2.662 \times 10^{-4}$ \\
GA-ITSE & $-7.186 \times 10^{-3}$ & 0.7239 & 9.012 & $-3.151 \times 10^{-4}$ \\
PSO-ITAE & $-6.997 \times 10^{-3}$ & 0.7166 & 8.695 & $-2.636 \times 10^{-4}$ \\
PSO-ITSE & $-7.061 \times 10^{-3}$ & 0.6968 & 8.738 & $-2.825 \times 10^{-4}$ \\
Ref. [18] & $-7.6 \times 10^{-3}$ & None & 10.42 & None \\
Ref. [19] & $-9.3 \times 10^{-3}$ & None & 9.5 & None \\
\hline
\end{tabular}

Figures 9 and 10 shows the terminal voltage response to the PID controller adjustment by FA, GA and PSO based on ITAE and ITSE compared with conventional (Z-N) method, while the characteristics of the terminal voltage (maximum-peak, peak-time, then settling-time and finaly steady-state-error) are given in Table 6 compared with results are presented in papers $[18,19]$.

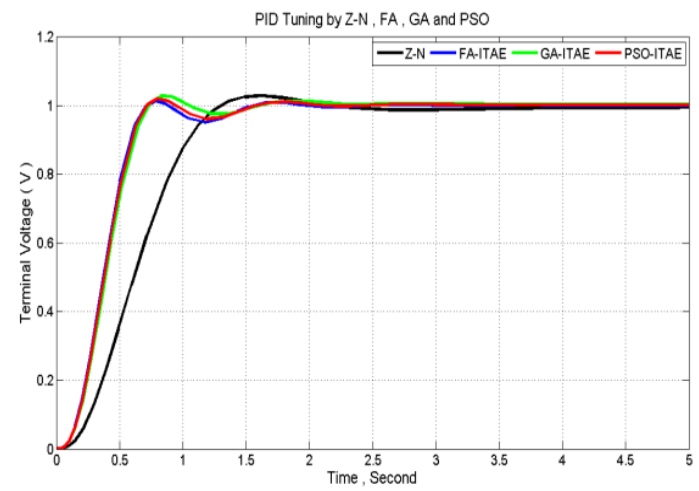

Figure 9. Terminal Voltage with PID tuning by FA, GA and PSO based on ITAE compared with Z-N

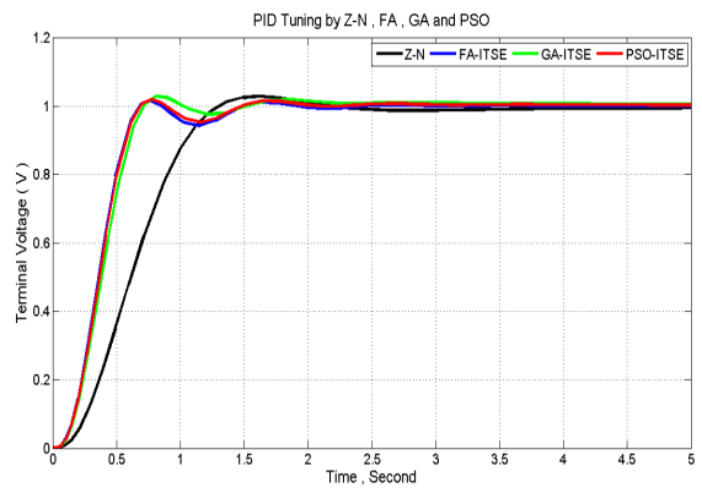

Figure 10. Terminal Voltage with PID tuning by FA, GA and PSO based on ITSE compared with Z-N

Table 6. Terminal Voltage Characteristics with PID Tuning by Z-N, FA, GA and PSO

\begin{tabular}{|c|c|c|c|c|}
\hline & $\mathrm{M}_{\mathrm{p}}$ (p.u) & $\mathrm{t}_{\mathrm{p}}(\mathrm{sec})$. & $\mathrm{t}_{\mathrm{s}}$ (sec.) & $\mathrm{E}_{\mathrm{ss}}$ (p.u) \\
\hline Z-N & 1.029 & 1.625 & 1.933 & $5.3 \times 10^{-3}$ \\
\hline FA-ITAE & 1.013 & 0.7849 & 1.422 & $-1 \times 10^{-3}$ \\
\hline FA-ITSE & 1.015 & 0.7679 & 1.383 & 0 \\
\hline GA-ITAE & 1.027 & 0.8218 & 1.439 & $-3 \times 10^{-3}$ \\
\hline GA-ITSE & 1.028 & 0.8085 & 1.396 & $-5 \times 10^{-3}$ \\
\hline PSO-ITAE & 1.019 & 0.7995 & 1.432 & $-2 \times 10^{-3}$ \\
\hline PSO-ITSE & 1.019 & 0.7766 & 1.385 & $-3 \times 10^{-3}$ \\
\hline Ref. [18] & 1.204 & None & 9.3 & None \\
\hline Ref. [19] & 1.0 & None & 4.9 & None \\
\hline
\end{tabular}

Figure 11 illustrates the convergence in reducing the ITAE index using FA, GA and PSO to determine the optimal values for a PID controller. While, Figure 12 illustrates the convergence in reducing the ITSE index using FA, GA, and PSO to determine the optimal values for a PID controller. Therefore; these convergence curves show that FA has better performance than GA and PSO. 


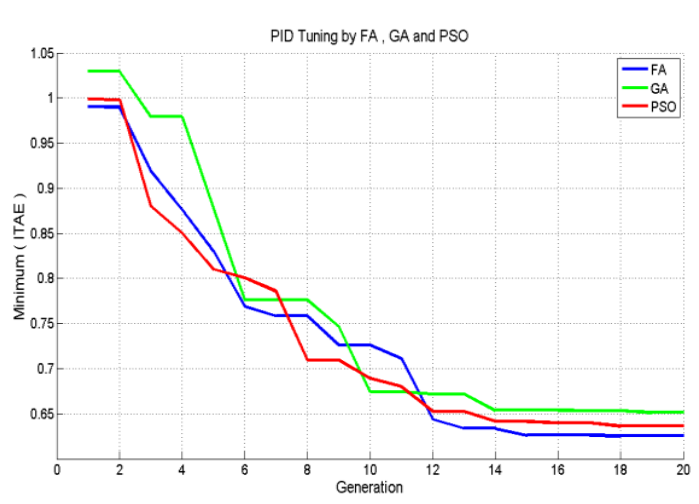

Figure 11. Convergence curve of FA, GA then PSO for optimal gains for PID with minimize ITAE

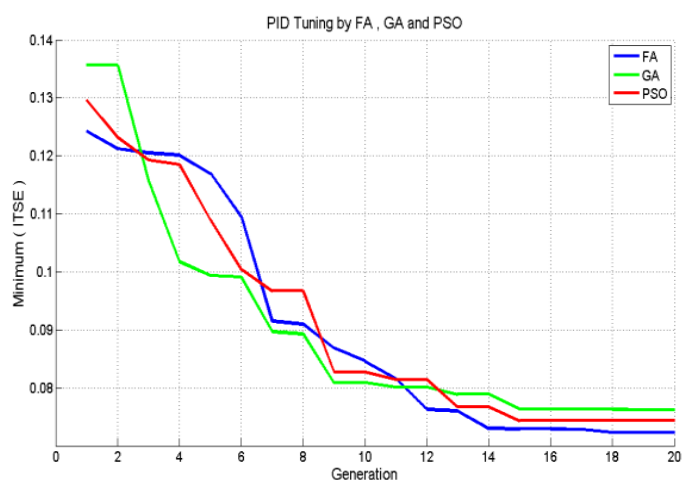

Figure 12. Convergence curve of FA, GA then PSO for optimal gains for PID with minimize ITSE

In all the results above, the overall characteristics of the frequency deviation and the terminal voltage are reduced by FA, GA and PSO for tuning of the PID controller when compared with conventional (Z-N) PID controller, the damping characteristics of single area power system with tuning the PID controller by FA are improved more effectively compared with GA and PSO. Also, stability of single area power system is conserved and reduced for power system oscillations.

\section{CONCLUSION}

This paper studied the PID control performance taking the coupling effect between LFC and AVR, at first using the conventional PID controller (Z-N) method to improve the performance of these loops, and then for faster tune of PID controller and for obtain the results more accurate, we used the modern intelligence techniques such as FA, GA and PSO. Demonstrated by the results that were obtained and compared between the three techniques mentioned previously, observed that FA has a clear progress over than GA and PSO for tuning the PID gains to enhanced the overall characteristics of the terminal voltage and frequency oscillation for single area power system.

\section{REFERENCES}

[1] P. Kundur, "Power System Stability and Control," McGraw Hill, New York, 1994.

[2] H. Saddat, "Power System Analysis," McGraw Hill, New York, 1999.

[3] W. G. Heffron and R. A. Phillips, "Effects of Modern Amplidyne Voltage Regulator in Underexcited Operation of Large Turbine Generators," AIEE Trans., PAS-71, pp.692-697, Aug. 1952.

[4] F. P. DeMello and C. Concordja, "Concepts of Synchronous Machine Stability as Affected by Excitation Control," IEEE Trans., PAS-88, pp.316- 329, Apr. 1969.

[5] E. Rakhshani, K. Rouzbehi and S. Sadeh, "A New Combined Model for Simulation of Mutual Effects between LFC and AVR Loops," Proceeding on Asia-Pacific Power and Energy Engineering Conference, (APPEEC 2009), Wuhan, China, 2009.

[6] B. U. Musa, B. M. Kalli and K. Shettima, "Modeling and Simulation of LFC and AVR with PID Controller," International Journal of Engineering Science Invention, vol. 2, Issue 7, pp.54-57, July 2013.

[7] S. Satyanarayana, R. K. Sharma and Mukta, "Mutual Effect between LFC and AVR Loops in Power Plant," Electrical and Electronics Engineering: An International Journal (ELELIJ), vol. 3, no.1, pp. 61-69, February 2014.

[8] M. Najeeb, et al., "An Optimal LFC in Two-Area Power Systems Using a Meta-heuristic Optimization Algorithm," International Journal of Electrical and Computer Engineering (IJECE), vol/issue: 7(6), pp. 3217- 3225, 2017.

[9] B. M. Hussein, "A new scaled fuzzy method using PSO segmentation (SePSO) applied for two area power system," International Journal of Electrical and Computer Engineering (IJECE), vol/issue: 9(2), pp. 815-825, 2019.

[10] K. Naidu, H. Mokhlisa and A. H. Bakar, "Application of Firefly Algorithm (FA) based optimization in load frequency control for interconnected reheat thermal power system," IEEE Jordan Conference on Applied Electrical Engineering and Computing Technologies (AEECT), 2013.

[11] G. Konar, K. K. Mandal, and N. Chakraborty, "Two Area Load Frequency Control Using GA Tuned PID Controller in Deregulated Environment," Proceedings of the International MultiConference of Engineers and Computer Scientists 2014, vol. II, IMECS 2014, March 12 - 14, Hong Kong, 2014. 
[12] G. A. Salman, "Automatic Generation Control in Multi Area Interconnected Power System Using PID Controller Based on GA and PSO," Second Engineering Scientific Conference, College of Engineering, University of Diyala, pp. 297-310, 2015.

[13] Z. L. Gaing, "A Particle Swarm Optimization Approach for Optimum Design of PID Controller in AVR System," IEEE Transactions on Energy Conversion, vol. 19, no. 2, June 2004, pp.384-391.

[14] N. R. Raju, et al., "Robustness Study of Fractional Order PID Controller Optimized by Particle Swarm Optimization in AVR System," International Journal of Electrical and Computer Engineering (IJECE), vol/issue: 6(5), pp. 2033-2040, 2016.

[15] A. Kumar and R. Gupta, "Compare the results of Tuning of PID controller by using PSO and GA Technique for AVR system," International Journal of Advanced Research in Computer Engineering \& Technology (IJARCET), vol. 2, Issue 6, pp.2130-2138, June 2013.

[16] S. A. HashemiZadeh and H. F. Marj, "The analysis and comparison of PSO and BGA algorithms for design of PID controller in Automatic Voltage Regulation (AVR) system," Advances in Natural and Applied Sciences, 8(11) Special 2014, pp. 56-70, 2014.

[17] N. Nayak, S. K. Routray and S. Pradhan, "Optimal Design of PID Controller for AVR in a multi Machine Power System using Modified PSO and Fire Fly Optimization Technique," IEEE Power, Communication and Information Technology Conference (PCITC), Siksha 'O’ Anusandhan University, Bhubaneswar, India, 2015.

[18] A. Soundarrajan, S. Sumathi and C. Sundar, "Particle Swarm Optimization Based LFC and AVR of Autonomous Power Generating System," IAENG International Journal of Computer Science (IJCS), 37:1, February 2010.

[19] A. Soundarrajan, S. Sumathi and G. Sivamurugan, "Hybrid Evolutionary Algorithms for Frequency and Voltage Control in Power Generating," ICTACT Journal on Soft Computing, Issue: 02 October 2010, pp.88-97.

[20] A. M. Hamza, M. S. Saad, H. M. Rashad and A. Bahgat, "Design of LFC and AVR for Single Area Power System with PID Controller Tuning By BFO and Ziegler Methods," International Journal of Computer Science and Telecommunications, vol. 4, Issue 5, May 2013, pp.12-17.

[21] N. Y. Kouba, M. Menaa, M. Hasni and M. Boudour, "Optimal Control of Frequency and Voltage Variations Using PID Controller Based on Particle Swarm Optimization," Proceedings of the 4th International Conference on Systems and Control, Sousse, Tunisia, April 28-30, 2015.

[22] G. A. Salman, H. I. Hussein and M. S. Hasan, "Enhancement The Dynamic Stability of The Iraq's Power Station Using PID Controller Optimized by FA and PSO Based on Different Objective Functions," Elektrotehniški Vestnik, vol. 85, Issue (1-2), pp.42-48, 2018.

[23] S. Das, A.Chakraborty, J. K. Ray, S.Bhattacharjee and B. Neogi, "Study on Different Tuning Approach with Incorporation of Simulation Aspect for Z-N (Ziegler-Nichols) Rules," International Journal of Scientific and Research Publications, Volume 2, Issue 8, August 2012, pp.1-5.

[24] J. G. Ziegler and N.B. Nichols, "Optimum Settings for Automatic Controllers," Trans. ASME, Vol. 64, pp.759-768, 1942.

[25] K. Ogata, "Modern Control Engineering," Prentice Hall, Upper Saddle River, New Jersey, 1997.

[26] X. S. Yang, "Nature-Inspired Metaheuristic Algorithms," Luniver Press, 2008.

[27] D. Rerkpreedapong, A. Hasanovic and A. Feliachi, "Robust Load Frequency Control Using Genetic Algorithms and Linear Matrix Inequalities," IEEE Transactions on Power Systems, Vol. 18, No. 2, pp.855-861, May 2003.

[28] G. A. Salman, M. H. Ali and A. N. Abdullah, "Implementation Optimal Location and Sizing of UPFC on Iraqi Power System Grid (132 kV) Using Genetic Algorithm,” International Journal of Power Electronics and Drive System (IJPEDS), vol/issue: 9(4), pp. 1607-1615, 2018.

[29] I. Azim and F. Rahman, "Genetic Algorithm Based Reactive Power Management by SVC," International Journal of Electrical and Computer Engineering (IJECE), vol/issue: 4(2), pp. 200-206, 2014.

[30] J. Kennedy and R. Eberhart, "Particle Swarm Optimization," Proceeding of the IEEE International Conference on Neural Networks, vol. IV, pp.1942-1948, 1995. 


\section{BIBLIOGRAPHY OF AUTHORS}

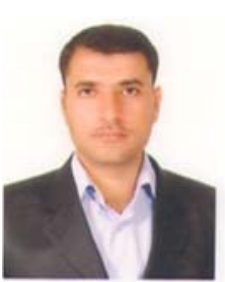

Ghassan Abdullah Salman was born in Diyala, Iraq, in 1983, received his B.Sc. from University Diyala / Iraq in 2006, M. Sc. from university of technology, Baghdad, Iraq in 2011. He is currently senior lecturer in the Department of Electrical Power Engineering, College of Engineering, University of Diyala Iraq. He has three years of Industrial experience and electrical companies and has teaching experience. His research interests are optimal power system, power system operation and control, FACTS devices, power system security and power Quality. He has 10 published papers.

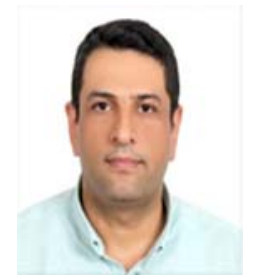

Assama Sahib Jafar Al-Ghanimi, is a lecturer assistant in college of engineering, department of electrical power and machines department in university of Diyala. Born in Iraq, 1975, he got his BSc. Degree in electrical engineering from Baghdad university 1996, MSc. Degree in electrical and control engineering from Jordan university of Science and technology (Jordan) 2003. His main interest in the control field, fuzzy-Logic control, electrical drives and power systems stability studies.

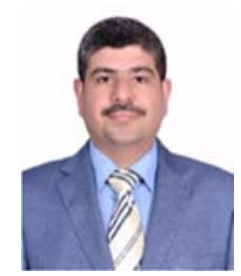

Ammar Issa Ismael received his B.Sc from University of Baghdad in Iraq in 2001, MSc from University Tenaga nosional (uniten) in Malaysia at 2013, has four years experience in industrial of inverter and electrical equipment then work at college of engineering University of Diyala, Iraq as assistant lecture and laboratories of the electrical power and machine engineering. He has current research interests include power electronic, electrical car, renable energy. 